\title{
How not to be seen: immune-evasion strategies in gene therapy
}

\author{
A Zaldumbide and RC Hoeben \\ Department of Molecular Cell Biology, Leiden University Medical Center, Leiden, The Netherlands
}

The development of efficient and safe vectors for gene delivery paved the way for evolution of gene therapy as a new modality for treatment of various inherited disorders and for cancer. The current vectors, viral and non-viral, have their limitations. Innate and adaptive immune responses to vector particles and components may restrict the efficiency of gene transfer and the persistence of expression of the transgene. Results from preclinical studies in animals and more recently data from clinical studies have demonstrated the potential impact of the cellular and the humoral immune response on the therapeutic efficacy. Not only the vector components, but

Keywords: CTL; transgene; herpes virus; $M H C$

\section{The immune system as foe of the gene therapist}

During maturation, thymocytes undergo a quality control process to eliminate clones that recognize self-antigens. Gene therapy may lead to the expression of neo-antigens, resulting in the induction of an immune response and cytotoxic destruction of the modified cells. Many preclinical and clinical studies have demonstrated the magnitude of this problem and identified a number of variables that can affect the immune response, as outlined below.

\section{Responses against the transgene product}

In Duchenne's muscular dystrophy, dystrophin gene delivery appears to be a promising treatment to restore the cytoskeletal integrity in the muscle fibers. However, the induction of an immune response against dystrophin was observed after cardiac transplantation of myoblasts in dystrophic patients. ${ }^{1,2}$ A dystrophin-specific cytotoxic T-cell response was noted after injection of the human dystrophin gene as naked DNA into $m d x$ mice, although human and mouse dystrophin proteins are more than $90 \%$ identical. ${ }^{3}$ It may therefore not be surprising that intramuscular injection of an adeno-associated virus (AAV) vector encoding a human microdystrophin

Correspondence: Professor RC Hoeben, Leiden University Medical Center, Postal Zone S1-P, PO Box 9600, Leiden 2300 RC, The Netherlands.

E-mail: R.C.Hoeben@lumc.nl

Received 9 July 2007; revised 29 September 2007; accepted 6 November 2007; published online 29 November 2007 also the transgene products may induce an immune response that negatively affects the therapeutic efficacy. The induction of a cytotoxic $T$-cell response to transgeneencoded peptides, as well as the production of antibodies directed against secreted proteins have been reported in preclinical and clinical studies, and these may thwart those applications that require long-term expression. Here we will review some of the options to blunt the acquired immune responses to transgene-encoded polypeptides.

Gene Therapy (2008) 15, 239-246; doi:10.1038/sj.gt.3303082; published online 29 November 2007

into $m d x$ mice triggered an immune response against dystrophin. ${ }^{4}$

An immune response may even be induced in patients expressing alleles with missense mutations, or with small in-frame deletions. In a recent study, Figueredo et al. ${ }^{5}$ used a major histocompatibility complex (MHC)-binding prediction program to estimate the probability of a cellular immune response against the $\Delta$ F508 product of the cystic fibrosis transmembrane conductance regulator gene (CFTR), which is the most prevalent mutant protein found in cystic fibrosis disease patients. Several highscoring MHC class I binders were identified within the specific sequences. These data suggest that there is a significant probability that the host mounts a cellular immune response against CFTR, even if the difference between therapeutic and host's CFTR is only a single amino acid.

Obviously, if gene replacement therapy with a gene that is highly similar to the one of the host can trigger a transgene-specific immune response, the synthesis of a foreign gene product is likely to generate a similar response. This has been evident from a clinical study involving donor lymphocyte infusion. Donor T cells were administered to leukemia patients to induce a graftversus-leukemia (GvL) immune response. This effect should eradicate residual leukemic cells that survived the cytoablative therapy. At the same time, however, the recipients are at risk to develop a graft-versus-host disease (GvHD). In order to selectively eradicate the infused lymphocytes in case GvHD develops, the donor lymphocytes are modified to express the herpes simplex virus (HSV) thymidine-kinase (tk) gene. The product of the HSV-tk gene converts the prodrug ganciclovir (GCV) into a phosphorylated derivative. ${ }^{6,7} \mathrm{GCV}$ phosphates are 
active compounds that induce cell death by inhibiting DNA synthesis. Therefore, HSV-tk-modified $\mathrm{T}$ cells can be selectively killed by administering GCV to the patients. ${ }^{8,9}$ However, in a clinical study 7 out the 23 patients treated developed a strong cytolytic T-lymphocytes (CTL) immune response against the HSV-tk protein, ${ }^{10}$ even though, in this particular example the immune response did not affect the efficacy of the therapy.

Pharmacological gene regulation is a key issue for safe gene therapy but here again its in vivo use can be hampered by immune rejection. The archetypical systems for regulated gene expression are the so-called Tet-On and Tet-Off systems. In these systems, the transcription of the gene of interest relies on the binding of the tetracycline/doxycycline-activated transactivator (rtTA) to the Tet-operator-controlled promoter. Simple intramuscular injection of plasmid or adenoviral vectors encoding rtTA in primates generates a cellular and humoral immune response against the transactivator protein and results in the destruction of the genemodified cells. ${ }^{11}$ Although extensive evolution yielded improved transactivator proteins, which require lower amounts of the activator, the transactivator proteins remain very immunogenic.

Other examples come from the fluorescent and bioluminescent reporter proteins that are popular for tracing genetically modified cells in vivo. The green fluorescent protein (GFP) that originates from jellyfish and similar proteins from other organisms facilitate monitoring the fate of the grafted genetically modified cells. Again, their utilization is limited in immune competent hosts by the destruction of the grafted cells by antigen-specific immune responses. ${ }^{12-15}$ In nonhuman primates, hematopoietic stem cells genetically modified by lentiviral vectors for the expression of GFP or yellow fluorescent protein (YFP) reporter genes were lost as a result of a CTL response to the modified cells in four out of five recipients.

\section{Transgene expression level and tissue specificity}

Gene therapy can correct the bleeding diathesis in hemophilia B. ${ }^{16}$ However, the development of specific antibodies (inhibitors) against the clotting factor may be a serious complication. Several animal studies demonstrated that gene therapy can induce factor IX (FIX) inhibitors. Direct intramuscular delivery of a human FIX cDNA expression vector triggered a strong FIX-specific immune response in immunocompetent mice ${ }^{17}$ and resulted in the generation of anticanine FIX antibodies in hemophilic dogs. ${ }^{18}$ Follenzi et al. observed a specific cellular and humoral response upon lentiviral transfer of the FIX cDNA when expression was driven by a ubiquitously active promoter (that is, the human cytomegalovirus (hCMV) immediate early enhancer and promoter). In contrast, no immune response was detected if the FIX gene was expressed under the control of a liver-specific promoter. ${ }^{19}$

Immune response against neo-antigens can also be illustrated by several approaches tested for anemia treatment. While erythropoietin (Epo) gene delivery with an AAV vector and under the control of a CMV promoter could result in a long-term and stable expression of the transgene, ${ }^{20,21}$ a transgene-specific immune response was observed following the implantation of encapsulated
Epo-secreting myoblasts. ${ }^{22}$ This apparent discrepancy may be explained by the nature of the recipient. In the first studies, the authors explored the efficacy of Epo delivery in healthy animals, whereas the latter one was carried out in a homozygous mouse model for severe anemia (that is, Epo-TAgh) in which the wild-type Epo gene was absent (disrupted by SV40 large T-antigen insertion). A recent study showed that the transgene expression level could also be a determining factor. Indeed, in a macaque model, intramuscular administration of AAV containing an Epo gene driven by the hCMV promoter causes polycythemia shortly after injection, breaks immune tolerance and leads to the development of autoimmune anemia. ${ }^{23}$

In addition to the transgene features, the gene-transfer vector used may affect the host's immune response (for review $\left.\mathrm{see}^{24,25}\right)$. For viral vectors the tropism may be critical. In mice that received the adenoviral vector, a transgene-specific CTL response was observed, whereas no CTL were detected after AAV2-mediated delivery. ${ }^{26}$ In an elegant study, Jooss et al. ${ }^{27}$ attributed the differences to the fact that AAV2 vectors, in contrast to adenovirus type 5 vectors, do not transduce the dendritic cells that function as antigen-presenting cells. The CTL response resulting from the activation of the $\mathrm{CD}^{+}$ T-helper cells eradicated the transduced cells and prevented long-term expression of the transgene.

It should be noted that although in most of the aforementioned examples viral vectors had been used for gene transfer, similar immune responses against the transgene products might be anticipated if efficient nonviral vectors are employed. Indeed, some DNA liposome complexes may be highly immunostimulatory. ${ }^{28,29}$

The immune system, our 'bodyguard', may frustrate many gene therapy applications by selectively eliminating the genetically modified cells. Thus, it is pivotal for the further advancement of gene therapy that the immune system is tamed and that the genetically modified cells are protected from the actions of the adaptive immune system.

\section{So what avenues are open to evade the effects of the immune system?}

\section{Reducing innate immune responses}

In addition to the acquired immune response, the innate immune system acts on viral pathogens. ${ }^{30}$ Toll-like receptors (TLR) found for example in dendritic cells and macrophages recognize pathogen-associated molecular patterns (PAMPs) in DNA, mRNA or double-strand RNA. Immediately after infection, the PAMPS-TLR interactions induce secretion of proinflammatory cytokines (mainly interferon $\alpha$ and $\beta$ ) and chemokines, which activate an adaptive immune response.

Recently, Yang and colleagues demonstrated the importance, in therapy, of inhibiting interferon signaling pathways. ${ }^{31}$ Mice pretreated with anti-IFN $\alpha$ or anti-IFN $\beta$ $6 \mathrm{~h}$ before an adenoviral vector infusion show an increase of the viral DNA copy number, a decrease in the virus-specific CTL response, and a long-term expression of the transgene. In their evolution, viruses developed various strategies to reduce the innate 
immune responses by inhibiting the interferon-signaling pathway. Examples of viral proteins that tamper with these pathways include A46R from vaccinia virus, ${ }^{32,33}$ the NS3/4A protease from hepatitis C virus, ${ }^{34}$ and the RTA ubiquitin ligase from the Kaposi sarcoma herpes virus. ${ }^{35}$ Adopting such viral-derived strategies for use in gene therapy vectors may allow blocking innate immune sensors and affect communication with the adaptive immune system and may constitute an attractive approach to reduce undesirable immune responses.

\section{Affecting T-cell function/anergy induction}

The most robust ways to prevent or suppress the immune responses are those currently used to prevent graft rejection in clinical organ transplantation. These rely on the utilization of general immunosuppressive treatment regimen, which can affect several T-cell subpopulations: inhibition of the regulatory $\mathrm{T}$ cells (that is, $\mathrm{CD} 4^{+} / \mathrm{CD} 25^{+}$) by cyclophosphamide treatment or blockage of T-cells activation by inhibiting interleukin production (cyclosporin, methotrexate). ${ }^{36-38}$ However, such treatments may have serious side effects, such as severe anemia, neutropenia, kidney or/and liver dysfunction, and lead to increased sensitivity to viral infections.

An insight in the relevant processes could provide new options to interfere with T-cell activation. Complete T-cell activation requires at least two signals: the first one originates from the direct interaction between the T-cell receptor (TCR) and the MHC class I peptide complex, and the second from the interaction between accessory molecules at the cell surface (CD40L/CD40 and CD28/ CTLA4-B7).

Interestingly, synthesis of soluble human CTLA4Ig, generated by fusing the extracellular domain of CTLA4 with the Fc domain of the IgG, leads to a prolonged state of T-cell unresponsiveness by blocking the CD28 signaling pathway in vitro. ${ }^{39,40}$ The feasibility of this approach was demonstrated by Kay et al. ${ }^{41}$ who showed that the co-administration of recombinant adenovirus with soluble murine CTLA4Ig yielded high expression of the transgene for up to 5 months after injection. In a transplantation protocol for diabetes treatment, transduction of pancreatic islets of Langerhans with adenovirus or lentivirus vectors expressing CTLA4Ig attenuate transplant rejection and prolongs glycemia maintenance in streptozotocin-treated mice. ${ }^{42,43}$ The importance of these co-stimulatory proteins in T-cell activation has been illustrated in a comparative study in which several immunosuppressive treatments were evaluated after human factor VIII (hFVIII) naked DNA transfer into hemophilia A mice. Ochs and co-workers demonstrated that whereas blockage of either CD28/B7 or CD40L/ CD40 interaction is sufficient to delay FVIII-inhibitor formation, only the combined treatment CTLA4Ig/ anti-CD40 yielded a lasting immune tolerance to the neo-antigen and supraphysiologic levels of hFVIII in the mice. ${ }^{44}$

Similarly, administration of anti-inflammatory cytokines, such as IL-10 or TGF- $\beta$, can reduce the immune responses to allografts by inhibiting cytokine production and blocking T-cell activation. ${ }^{45-47}$ Intracoronary perfusion of the donor heart with an adenovirus expressing the Epstein-Barr virus IL-10 homologue (vIL-10), combined with a subtherapeutic dose of cyclosporine A, significantly prolonged graft survival from 10 to 36 days in a rat heart transplantation model. ${ }^{48}$ Remarkably, IL-10 is also able to prevent autoimmune diabetes in NOD mice since a single administration of an AAV vector carrying the vIL-10 gene postponed the onset of diabetes in young (3 weeks old) and prediabetic (6 weeks old) NOD mice. ${ }^{49}$ Moreover, the same approach protects transplanted islets from autoimmune destruction in a murine model. ${ }^{50}$

\section{Conditioning the recipient}

A small population (1-2\%) of $\mathrm{CD}^{+} \mathrm{T}$ cells controls immune homeostasis. The $\mathrm{CD}^{+} / \mathrm{CD}^{2} 5^{+} / \mathrm{FoxP} 3$ regulatory $\mathrm{T}$ cells (Tregs), stimulated by anti-inflammatory cytokines like IL-10 or TGF- $\beta$, induce self-tolerance by actively suppressing immune responses. Adapting Treg numbers could be an important approach for therapeutic treatment. Two possibilities should be considered: reducing Treg numbers for cancer therapy (in ovarian cancer treatment, clinical observations correlated the poor survival rate with an infiltration of these 'inhibitory' $\mathrm{T}$ cells), ${ }^{51}$ or activating Tregs to induce transplantation tolerance (for review see Wood and Sakaguchi ${ }^{52}$ ) or selftolerance to autoantigens. ${ }^{53,54}$ Experiments performed in NOD mice revealed that injection of islet-specific Tregs reversed hyperglycemia in $50 \%$ of the treated mice. ${ }^{55}$ However, Tregs activation could be also an important issue to circumvent immune rejection of transgenemodified cells. Experiments performed in murine and canine models demonstrated that AAV-mediated hepatic FIX gene transfer can induce, by an as yet unidentified mechanism, tolerance to the transgene product. ${ }^{56-58}$ Interestingly when splenocytes from tolerized mice were transferred into naive mice, prolonged FIX gene expression was observed even after injection of a potent CTL activator (that is, Ad-FIX). In contrast, mice that received non-tolerized or CD4-depleted splenocytes lost FIX gene expression in the liver. ${ }^{59}$ Recently, the same group points out the contribution of the Treg population by depleting the $\mathrm{CD}^{+} / \mathrm{CD} 25^{+}$subset: four out of the five mice that received the mouse anti-CD25 antibody treatment developed FIX inhibitors within 6 weeks after AAV-hFIX injection into the liver. ${ }^{60}$

\section{Humanizing gene products}

To prevent the immune responses against transgene products several groups investigated the feasibility of using autologous (self) gene products to reduce the cytotoxic immune response in human recipients. Among others, inducible 'humanized' caspase 8,61 FasL $^{62}$ and $\mathrm{CD} 20^{63}$ were developed to circumvent the immune responses that may restrict the use of viral or bacterial suicide genes, such as the HSV-tk gene. However, it remains to be evaluated whether building the suicide genes from human components suffices for preventing the induction of an immune response.

\section{Restricting expression of the transgene}

The use of cell type-specific promoters to target transgene expression has been advocated as an efficient means to reduce transgene expression in professional antigen-presenting cells such as dendritic cells. Although several studies provided evidence for the effectiveness of this approach, others still reported immune reactions against the transgene product. ${ }^{19,64}$ More recently, the endogenous expression of specific microRNAs was used 
to prevent expression of the transgene in the hematopoietic lineage. Indeed, endogenous non-coding RNA (20-23 nucleotides long) can assemble into a RNA-induced silencing complex (RISC) to post-transcriptionally repress gene expression (for review see Rana ${ }^{65}$ ). A miRNAregulated lentiviral vector was developed which contains the target sequence of the hematopoietic-lineage-specific miRNA mir-142-3p. This de-targets transgene expression in hematopoietic cells and results in an effective suppression of expression in intravascular and extravascular hematopoietic lineages, without affecting the expression level in non-hematopoietic cell types. ${ }^{66}$ Recently, the same group further validated the potential of this approach by treating hemophilia B mice with a lentivirus carrying both FIX and the mir-142-3p target. Interestingly, the treated mice maintained FIX expression for over 9 months without detectable anti-FIX humoral immune responses. ${ }^{67}$ Hence, the exploitation of miRNA may constitute a promising approach to prevent adapted immune responses against transgene products.

\section{Protecting the modified cells}

A radically different approach to protect the genemodified cells may employ virus-derived immuneevasion mechanisms. Many viruses, and especially members of the herpes virus family, have developed very effective immune-evasion systems in particular by reducing generation of antigenic peptides and their presentation in the context of MHC class I molecules.

The presentation of antigenic peptides by MHC class I molecules and the recognition of this complex by CTLs is the final step in a cascade of processes starting in the cytoplasm. Here the proteins are degraded by the proteasome, generating small antigenic peptides. These peptides enter the endoplasmic reticulum via the transporter associated with antigen processing (TAP) proteins, where they are captured by the MHC class I complex. The peptide-loaded complex is routed via the Golgi system to be expressed at the cell surface. Viruses interfere with these process at all levels to evade the immune system (for review see Loenen et al. ${ }^{68}$ and Vossen et al. ${ }^{69}$ ). The US2 and US11 proteins from hCMV cause a rapid degradation of newly synthesized $\mathrm{MHC}$ class I heavy chains, ${ }^{70,71}$ the US3 protein retains the MHC-I in the endoplasmic reticulum, ${ }^{72}$ MIR1 and MIR2 from human herpes virus 8 (HHV8) and Nef from the human immunodeficiency virus downregulate $\mathrm{MHC}$ class I expression on the cell surface, ${ }^{73-76}$ ICP47 from HSV and UL49.5 from bovine herpes virus 1 act as competitive inhibitors of the peptide/TAP complex, ${ }^{77,78}$ and the US6 protein from hCMV inhibits peptide translocation. ${ }^{79}$ These mechanisms to prevent neo-antigens presentation and to protect genetically modified cells are currently being evaluated. However, whereas some studies with ICP47 support its protective effect, ${ }^{80,81}$ the reduced amounts of MHC class I molecules may make the modified cells more sensitive to NK cell activity. ${ }^{82,83}$ Experiments in non-human primates, using adenovirus vector that co-express ICP47 and the CFTR gene, indeed suggest an increased NK cell sensitivity of the gene-modified cells. ${ }^{84}$

The feasibility of this approach has also been elegantly demonstrated by Horwitz and colleagues in a diabetes model. ${ }^{85}$ Type I autoimmune diabetes destroys islets by mechanisms that involve MHC class I molecules and tumor necrosis factor $\alpha(\mathrm{TNF}-\alpha)$. In the well-studied lymphocytic choriomeningitis viral (LCMV) murine model of virus-induced autoimmune diabetes, an LCMV polypeptide expressed on the islets is a target for autoimmune destruction of $\beta$ cells after LCMV infection. The authors studied whether the human adenovirus type 2 E3 genes, which code for proteins implicated in the MHC class I downregulation and in inhibition of TNF- $\alpha$ / Fas-induced cytolysis, could protect islets from immune destruction. To this end, transgenic mouse expressing Ad E3 genes under the control of a rat insulin promoter were generated and crossed with LCMV mice. Eight months after, it appeared that none of the ten double transgenic mice (RIP-LCMV $\times$ RIP-AdE3) developed diabetes. A similar strategy could also be exploited in a gene therapy setting, by co-expression of the therapeutic gene with one or more viral immune-evasion genes.

\section{Generation of 'immuno-stealth' proteins}

Rather than preventing the cells capacity to present peptides via MHC class I molecules altogether, the transgene product can be protected from proteasomal degradation. This effectively makes the gene product invisible to the immune system. Pioneering experiments of Masucci and co-workers demonstrated that a specific sequence from the Epstein-Barr virus nuclear antigen 1 (EBNA-1) has the capacity to inhibit proteasomal degradation of linked antigens. ${ }^{86,87}$ We and others have exploited this mechanism to generate 'immunostealth' forms of some gene products frequently used in experimental gene therapy research, such as Escherichia coli $\beta$-galactosidase, HSV-tk and GFP. ${ }^{88-90}$ This was achieved by fusing codons for the 238-amino-acid-long glycine-alanine repeat (GAr) at the N-terminus of the reporter or therapeutic genes. Although antigen-specific CTLs were induced in mice after adenovirus-mediated transfer of minigenes encoding GAr-modified model antigens, the CTL neither in vitro nor in vivo react to cells producing these antigens. This is consistent with the model that the GAr inhibits generation of antigenic peptide from the fusion proteins. ${ }^{89}$ Importantly, the fusion proteins retained their biological activity.

However, degradation of normal proteins by the proteasome is only responsible for a small fraction of the antigenic peptides expressed on the cell surface. Most antigenic peptides are derived from defective products of proteins synthesis (DRiPs), including prematurely terminated products, misfolded proteins and frameshifted products. ${ }^{91,92}$ We recently provided evidence that EBNA-1 harbors a mechanism that may reduce unconventional epitope generation. Translation of the EBNA-1 mRNA from another open reading frame would yield a product that contains repeat sequence consisting solely of glycine, glutamine and glutamic acid residues (GZr). This repeat sequence, too, is able to inhibit proteasomal degradation of linked antigens. ${ }^{93}$ Intriguingly, neither the GAr nor the GZr elements prevent antigenic peptide generation in trans, that is, presentation of antigens derived from other proteins.

An important aspect to note is that the use of these inhibitory sequences may not be limited to the transgene product itself. In a phase 1-2 clinical study, Kay and collaborators demonstrated that infusion into the hepatic artery of a recombinant AAV vector carrying the human FIX cDNA into patients with hemophilia $B$, resulted in a 
decline of FIX level 8 weeks after treatment in some patients. ${ }^{94} \mathrm{~A}$ similar strategy gave very promising results in hemophilic dogs. ${ }^{95,96}$ IFN $\gamma$ assays established that the transaminase elevation, a consequence of destruction of transduced hepatocytes, was not due to an immune response against the transgene product itself, although a response against unconventional epitopes can not be fully excluded. Rather the response may be directed against the AAV capsid proteins. The authors attributed the difference observed between experimental models and human to the fact that during childhood many humans are infected by AAV2 and this infection often accompanied by adenovirus infection results in the formation of $\mathrm{CD}^{+} \mathrm{T}$ cells directed against antigens from the helper adenovirus and against AAV-derived peptides. $^{97}$ Therefore, two attractive approaches could be envisioned to circumvent this immune response to capsid proteins: induction of tolerance, like it has been reported in non-human primates ${ }^{98}$ and modification of AAV capsids proteins with sequences, such as the GAr or GZr elements, in order to generate an 'immunostealthed' therapeutic vector.

Although latency-associated proteins in other herpes viruses do not contain GAr or GAr-like motifs, the LANA-1 protein from HHV8, which has a function similar to EBNA-1, contains a protein domain with a high similarity with the GZr-domain. Also, this repeat can prevent presentation of antigenic peptides in the context of MHC class I molecules. ${ }^{99,100}$ Likewise, Bennett et al. ${ }^{101}$ identified that the ORF73 protein of the murine $\gamma$ herpes virus 68 (which is functionally equivalent to EBNA-1 and LANA-1), can block the antigen generation from linked polypeptides.

So far, the application of the 'immuno-stealthing' technology was hampered by the lengths of the repeat sequences, and the problems associated with stably maintaining such repeat sequences in E. coli. Shorter versions of these inhibitory sequences still have to be developed as inhibitors of antigen presentation. Studies have shown that shorter repeats can be equally or even more potent than the full-length repeats in preventing presentation of model antigens. Using the very unstable protein I b, Sharipo et al. ${ }^{102}$ demonstrated a GAr as short as 24 amino acids could increase I $k$ half-life, but it remains to be established whether such short elements are sufficient for immune evasion. Nevertheless, these in cis acting inhibitors of antigen presentation will be widely applicable for preventing the adaptive cellular responses against neo-antigens derived from transgene products and may enhance the long-term efficacy of many experimental gene therapy procedures.

The examples, mentioned above, provide several avenues for escaping the immune system. The immune-evasion strategy of choice may depend largely on the precise application for which it is intended, and may need further adaptation to provide optimal protection to the transduced cells. Nevertheless, the immune system should not be an insurmountable hurdle for longterm gene therapy anymore.

\section{Acknowledgements}

We thank Dr Françoise Carlotti, Dr Danijela KoppersLalic and Dr Twan de Vries for critical reading of the paper. This work was supported by the European Union through the 6th Framework Program GIANT (Contract no.: 512087), and by Diabetes Research Fund (DFN 2005.00.0212).

\section{References}

1 Bittner RE, Shorny S, Streubel B, Hubner C, Voit T, Kress W. Serum antibodies to the deleted dystrophin sequence after cardiac transplantation in a patient with Becker's muscular dystrophy. N Engl J Med 1995; 333: 732-733.

2 Tremblay JP, Malouin F, Roy R, Huard J, Bouchard JP, Satoh A et al. Results of a triple blind clinical study of myoblast transplantations without immunosuppressive treatment in young boys with Duchenne muscular dystrophy. Cell Transplant 1993; 2: 99-112.

3 Ferrer A, Wells KE, Wells DJ. Immune responses to dystropin: implications for gene therapy of Duchenne muscular dystrophy. Gene Therapy 2000; 7: 1439-1446.

4 Yuasa K, Sakamoto M, Miyagoe-Suzuki Y, Tanouchi A, Yamamoto $\mathrm{H}$, Li J et al. Adeno-associated virus vector-mediated gene transfer into dystrophin-deficient skeletal muscles evokes enhanced immune response against the transgene product. Gene Therapy 2002; 9: 1576-1588.

5 Figueredo J, Limberis M, Wilson JM. Prediction of cellular immune responses against CFTR in cystic fibrosis patients after gene therapy. Am J Respir Cell Mol Biol 2007; 36: 529-533.

6 Pulkkanen KJ, Parkkinen JJ, Laukkanen JM, Kettunen MI, Tyynela K, Kauppinen RA et al. HSV-tk gene therapy for human renal cell carcinoma in nude mice. Cancer Gene Ther 2001; 8: 529-536.

7 Pulkkanen KJ, Laukkanen JM, Fuxe J, Kettunen MI, Rehn M, Kannasto JM et al. The combination of HSV-tk and endostatin gene therapy eradicates orthotopic human renal cell carcinomas in nude mice. Cancer Gene Ther 2002; 9: 908-916.

8 Bonini C, Ferrari G, Verzeletti S, Servida P, Zappone E, Ruggieri $\mathrm{L}$ et al. HSV-TK gene transfer into donor lymphocytes for control of allogeneic graft-versus-leukemia. Science 1997; 276: 1719-1724.

9 Bonini C, Ciceri F, Marktel S, Bordignon C. Suicide-genetransduced T-cells for the regulation of the graft-versusleukemia effect. Vox Sang 1998; 74 (Suppl 2): 341-343.

10 Traversari C, Marktel S, Magnani Z, Mangia P, Russo V, Ciceri F et al. The potential immunogenicity of the TK suicide gene does not prevent full clinical benefit associated with the use of TKtransduced donor lymphocytes in HSCT for hematologic malignancies. Blood 2007; 109: 4708-4715.

11 Latta-Mahieu M, Rolland M, Caillet C, Wang M, Kennel P, Mahfouz I et al. Gene transfer of a chimeric trans-activator is immunogenic and results in short-lived transgene expression. Hum Gene Ther 2002; 13: 1611-1620.

12 Hanazono Y, Terao K, Shibata H, Nagashima T, Ageyama N, Asano $\mathrm{T}$ et al. Introduction of the green fluorescent protein gene into hematopoietic stem cells results in prolonged discrepancy of in vivo transduction levels between bone marrow progenitors and peripheral blood cells in nonhuman primates. J Gene Med 2002; 4: 470-477.

13 Moens U, Mathiesen I, Ghelue MV, Rekvig OP. Green fluorescent protein modified to bind DNA initiates production of anti-DNA antibodies when expressed in vivo. Mol Immunol 2002; 38: 505-514.

14 Rosenzweig M, Connole M, Glickman R, Yue SP, Noren B, DeMaria $\mathrm{M}$ et al. Induction of cytotoxic $\mathrm{T}$ lymphocyte and antibody responses to enhanced green fluorescent protein following transplantation of transduced CD34(+) hematopoietic cells. Blood 2001; 97: 1951-1959. 
15 Stripecke R, Carmen VM, Skelton D, Satake N, Halene S, Kohn D. Immune response to green fluorescent protein: implications for gene therapy. Gene Therapy 1999; 6: 1305-1312.

16 Snyder RO, Miao C, Meuse L, Tubb J, Donahue BA, Lin HF et al. Correction of hemophilia $\mathrm{B}$ in canine and murine models using recombinant adeno-associated viral vectors. Nat Med 1999; 5: 64-70.

17 Ge Y, Powell S, Van Roey M, McArthur JG. Factors influencing the development of an anti-factor IX (FIX) immune response following administration of adeno-associated virus-FIX. Blood 2001; 97: 3733-3737.

18 Mount JD, Herzog RW, Tillson DM, Goodman SA, Robinson N, McCleland ML et al. Sustained phenotypic correction of hemophilia B dogs with a factor IX null mutation by liverdirected gene therapy. Blood 2002; 99: 2670-2676.

19 Follenzi A, Battaglia M, Lombardo A, Annoni A, Roncarolo MG, Naldini L. Targeting lentiviral vector expression to hepatocytes limits transgene-specific immune response and establishes long-term expression of human antihemophilic factor IX in mice. Blood 2004; 103: 3700-3709.

20 Zhou S, Murphy JE, Escobedo JA, Dwarki VJ. Adeno-associated virus-mediated delivery of erythropoietin leads to sustained elevation of hematocrit in nonhuman primates. Gene Therapy 1998; 5: 665-670.

21 Kessler PD, Podsakoff GM, Chen X, McQuiston SA, Colosi PC, Matelis LA et al. Gene delivery to skeletal muscle results in sustained expression and systemic delivery of a therapeutic protein. Proc Natl Acad Sci USA 1996; 93: 14082-14087.

22 Rinsch C, Dupraz P, Schneider BL, Deglon N, Maxwell PH, Ratcliffe PJ et al. Delivery of erythropoietin by encapsulated myoblasts in a genetic model of severe anemia. Kidney Int 2002; 62: 1395-1401.

23 Gao G, Lebherz C, Weiner DJ, Grant R, Calcedo R, McCullough $\mathrm{B}$ et al. Erythropoietin gene therapy leads to autoimmune anemia in macaques. Blood 2004; 103: 3300-3302.

24 Hughes V. Therapy on trial. Nat Med 2007; 13: 1008-1009.

25 Schagen FH, Ossevoort M, Toes RE, Hoeben RC. Immune responses against adenoviral vectors and their transgene products: a review of strategies for evasion. Crit Rev Oncol Hematol 2004; 50: 51-70.

26 Fields PA, Kowalczyk DW, Arruda VR, Armstrong E, McCleland ML, Hagstrom JN et al. Role of vector in activation of T cell subsets in immune responses against the secreted transgene product factor IX. Mol Ther 2000; 1: 225-235.

27 Jooss K, Yang Y, Fisher KJ, Wilson JM. Transduction of dendritic cells by DNA viral vectors directs the immune response to transgene products in muscle fibers. J Virol 1998; 72: 4212-4223.

28 Dow SW, Fradkin LG, Liggitt DH, Willson AP, Heath TD, Potter TA. Lipid-DNA complexes induce potent activation of innate immune responses and antitumor activity when administered intravenously. J Immunol 1999; 163: 1552-1561.

29 Whitmore M, Li S, Huang L. LPD lipopolyplex initiates a potent cytokine response and inhibits tumor growth. Gene Therapy 1999; 6: 1867-1875.

30 Akira S, Uematsu S, Takeuchi O. Pathogen recognition and innate immunity. Cell 2006; 124: 783-801.

31 Zhu J, Huang X, Yang Y. Innate immune response to adenoviral vectors is mediated by both Toll-like receptor-dependent and -independent pathways. J Virol 2007; 81: 3170-3180.

32 Stack J, Haga IR, Schroder M, Bartlett NW, Maloney G, Reading PC et al. Vaccinia virus protein A46R targets multiple Toll-likeinterleukin-1 receptor adaptors and contributes to virulence. J Exp Med 2005; 201: 1007-1018.

33 Abe T, Kaname Y, Hamamoto I, Tsuda Y, Wen X, Taguwa S et al. Hepatitis $C$ virus nonstructural protein $5 \mathrm{~A}$ modulates the tolllike receptor-MyD88-dependent signaling pathway in macrophage cell lines. J Virol 2007; 81: 8953-8966.
34 Foy E, Li K, Sumpter Jr R, Loo YM, Johnson CL, Wang C et al. Control of antiviral defenses through hepatitis $\mathrm{C}$ virus disruption of retinoic acid-inducible gene-I signaling. Proc Natl Acad Sci USA 2005; 102: 2986-2991.

$35 \mathrm{Yu}$ Y, Wang SE, Hayward GS. The KSHV immediate-early transcription factor RTA encodes ubiquitin E3 ligase activity that targets IRF7 for proteosome-mediated degradation. Immunity 2005; 22: 59-70.

36 Ikezawa Y, Nakazawa M, Tamura C, Takahashi K, Minami M, Ikezawa Z. Cyclophosphamide decreases the number, percentage and the function of CD25+CD4+ regulatory T cells, which suppress induction of contact hypersensitivity. J Dermatol Sci 2005; 39: 105-112.

37 Lutsiak ME, Semnani RT, De Pascalis R, Kashmiri SV, Schlom J, Sabzevari H. Inhibition of CD4(+)25+ T regulatory cell function implicated in enhanced immune response by low-dose cyclophosphamide. Blood 2005; 105: 2862-2868.

38 Thomson AW, Bonham CA, Zeevi A. Mode of action of tacrolimus (FK506): molecular and cellular mechanisms. Ther Drug Monit 1995; 17: 584-591.

39 Judge TA, Tang A, Turka LA. Immunosuppression through blockade of CD28:B7-mediated costimulatory signals. Immunol Res 1996; 15: 38-49.

40 Lenschow DJ, Su GH, Zuckerman LA, Nabavi N, Jellis CL, Gray GS et al. Expression and functional significance of an additional ligand for CTLA-4. Proc Natl Acad Sci USA 1993; 90: 11054-11058.

41 Kay MA, Holterman AX, Meuse L, Gown A, Ochs HD, Linsley PS et al. Long-term hepatic adenovirus-mediated gene expression in mice following CTLA4Ig administration. Nat Genet 1995; 11: 191-197.

42 Feng S, Quickel RR, Hollister-Lock J, McLeod M, Bonner-Weir $\mathrm{S}$, Mulligan RC et al. Prolonged xenograft survival of islets infected with small doses of adenovirus expressing CTLA4Ig. Transplantation 1999; 67: 1607-1613.

43 Fernandes JR, Duvivier-Kali VF, Keegan M, Hollister-Lock J, Omer A, Su S et al. Transplantation of islets transduced with CTLA4-Ig and TGFbeta using adenovirus and lentivirus vectors. Transpl Immunol 2004; 13: 191-200.

44 Miao CH, Ye P, Thompson AR, Rawlings DJ, Ochs HD. Immunomodulation of transgene responses following naked DNA transfer of human factor VIII into hemophilia A mice. Blood 2006; 108: 19-27.

45 Bickerstaff AA, Wang JJ, Xia D, Orosz CG. Allograft acceptance despite differential strain-specific induction of TGF-beta/ IL-10-mediated immunoregulation. Am J Transplant 2002; 2: 819-827.

46 Ranges GE, Figari IS, Espevik T, Palladino MA, Jr. Inhibition of cytotoxic $\mathrm{T}$ cell development by transforming growth factor beta and reversal by recombinant tumor necrosis factor alpha. J Exp Med 1987; 166: 991-998.

47 Bejarano MT, de Waal MR, Abrams JS, Bigler M, Bacchetta R, de Vries JE et al. Interleukin 10 inhibits allogeneic proliferative and cytotoxic $\mathrm{T}$ cell responses generated in primary mixed lymphocyte cultures. Int Immunol 1992; 4: 1389-1397.

48 Zuo Z, Wang C, Carpenter D, Okada Y, Nicolaidou E, Toyoda $\mathrm{M}$ et al. Prolongation of allograft survival with viral IL-10 transfection in a highly histoincompatible model of rat heart allograft rejection. Transplantation 2001; 71: 686-691.

49 Carter JD, Ellett JD, Chen M, Smith KM, Fialkow LB, McDuffie MJ et al. Viral IL-10-mediated immune regulation in pancreatic islet transplantation. Mol Ther 2005; 12: 360-368.

50 Yang Z, Chen M, Wu R, Fialkow LB, Bromberg JS, McDuffie M et al. Suppression of autoimmune diabetes by viral IL-10 gene transfer. J Immunol 2002; 168: 6479-6485.

51 Wolf D, Wolf AM, Rumpold H, Fiegl H, Zeimet AG, Muller-Holzner $\mathrm{E}$ et al. The expression of the regulatory $\mathrm{T}$ cell-specific forkhead box transcription factor FoxP3 is 
associated with poor prognosis in ovarian cancer. Clin Cancer Res 2005; 11: 8326-8331.

52 Wood KJ, Sakaguchi S. Regulatory T cells in transplantation tolerance. Nat Rev Immunol 2003; 3: 199-210.

53 Lan RY, Ansari AA, Lian ZX, Gershwin ME. Regulatory T cells: development, function and role in autoimmunity. Autoimmun Rev 2005; 4: 351-363.

54 Battaglia M, Stabilini A, Draghici E, Migliavacca B, Gregori S, Bonifacio $\mathrm{E}$ et al. Induction of tolerance in type 1 diabetes via both $\mathrm{CD} 4+\mathrm{CD} 25+\mathrm{T}$ regulatory cells and $\mathrm{T}$ regulatory type 1 cells. Diabetes 2006; 55: 1571-1580.

55 Tarbell KV, Petit L, Zuo X, Toy P, Luo X, Mqadmi A et al. Dendritic cell-expanded, islet-specific CD4+ CD25+ CD62L+ regulatory $\mathrm{T}$ cells restore normoglycemia in diabetic NOD mice. J Exp Med 2007; 204: 191-201.

56 Ziegler RJ, Lonning SM, Armentano D, Li C, Souza DW, Cherry $\mathrm{M}$ et al. AAV2 vector harboring a liver-restricted promoter facilitates sustained expression of therapeutic levels of alphagalactosidase $\mathrm{A}$ and the induction of immune tolerance in Fabry mice. Mol Ther 2004; 9: 231-240.

57 Mingozzi F, Liu YL, Dobrzynski E, Kaufhold A, Liu JH, Wang Y et al. Induction of immune tolerance to coagulation factor IX antigen by in vivo hepatic gene transfer. J Clin Invest 2003; 111: 1347-1356.

58 Dobrzynski E, Herzog RW. Tolerance induction by viral in vivo gene transfer. Clin Med Res 2005; 3: 234-240.

59 Dobrzynski E, Fitzgerald JC, Cao O, Mingozzi F, Wang L, Herzog RW. Prevention of cytotoxic T lymphocyte responses to factor IX-expressing hepatocytes by gene transferinduced regulatory T cells. Proc Natl Acad Sci USA 2006; 103: 4592-4597.

60 Cao O, Dobrzynski E, Wang L, Nayak S, Mingle B, Terhorst C et al. Induction and role of regulatory CD4+CD25+ T cells in tolerance to the transgene product following hepatic in vivo gene transfer. Blood 2007; 110: 1132-1140.

61 Carlotti F, Zaldumbide A, Martin P, Boulukos KE, Hoeben RC, Pognonec P. Development of an inducible suicide gene system based on human caspase 8. Cancer Gene Ther 2005; 12: 627-639.

62 Thomis DC, Marktel S, Bonini C, Traversari C, Gilman M, Bordignon $\mathrm{C}$ et al. A Fas-based suicide switch in human T cells for the treatment of graft-versus-host disease. Blood 2001; 97: 1249-1257.

63 Serafini M, Manganini M, Borleri G, Bonamino M, Imberti L, Biondi A et al. Characterization of CD20-transduced $\mathrm{T}$ lymphocytes as an alternative suicide gene therapy approach for the treatment of graft-versus-host disease. Hum Gene Ther 2004; 15: 63-76.

64 Brown BD, Shi CX, Rawle FE, Tinlin S, McKinven A, Hough C et al. Factors influencing therapeutic efficacy and the host immune response to helper-dependent adenoviral gene therapy in hemophilia A mice. J Thromb Haemost 2004; 2: 111-118.

65 Rana TM. Illuminating the silence: understanding the structure and function of small RNAs. Nat Rev Mol Cell Biol 2007; 8: 23-36.

66 Brown BD, Venneri MA, Zingale A, Sergi SL, Naldini L. Endogenous microRNA regulation suppresses transgene expression in hematopoietic lineages and enables stable gene transfer. Nat Med 2006; 12: 585-591.

67 Brown BD, Cantore A, Annoni A, Sergi SL, Lombardo A, Della $\mathrm{VP}$ et al. A microRNA-regulated lentiviral vector mediates stable correction of hemophilia B mice. Blood 2007 [E-pub ahead of print; doi:10.1182/blood-2007-03-078493].

68 Loenen WA, Bruggeman CA, Wiertz EJ. Immune evasion by human cytomegalovirus: lessons in immunology and cell biology. Semin Immunol 2001; 13: 41-49.

69 Vossen MT, Westerhout EM, Soderberg-Naucler C, Wiertz EJ. Viral immune evasion: a masterpiece of evolution. Immunogenetics 2002; 54: 527-542.
70 Wiertz EJ, Tortorella D, Bogyo M, Yu J, Mothes W, Jones TR et al. Sec61-mediated transfer of a membrane protein from the endoplasmic reticulum to the proteasome for destruction. Nature 1996; 384: 432-438.

71 Wiertz EJ, Jones TR, Sun L, Bogyo M, Geuze HJ, Ploegh HL. The human cytomegalovirus US11 gene product dislocates MHC class I heavy chains from the endoplasmic reticulum to the cytosol. Cell 1996; 84: 769-779.

72 Ahn K, Angulo A, Ghazal P, Peterson PA, Yang Y, Fruh K. Human cytomegalovirus inhibits antigen presentation by a sequential multistep process. Proc Natl Acad Sci USA 1996; 93: 10990-10995.

73 Coscoy L, Ganem D. Kaposi's sarcoma-associated herpesvirus encodes two proteins that block cell surface display of MHC class I chains by enhancing their endocytosis. Proc Natl Acad Sci USA 2000; 97: 8051-8056.

74 Edelman DC. Human herpesvirus 8-a novel human pathogen. Virol J 2005; 2: 78.

75 Greenberg ME, Iafrate AJ, Skowronski J. The SH3 domainbinding surface and an acidic motif in HIV-1 Nef regulate trafficking of class I MHC complexes. EMBO J 1998; 17: 2777-2789.

76 Le Gall S, Buseyne F, Trocha A, Walker BD, Heard JM, Schwartz O. Distinct trafficking pathways mediate Nef-induced and clathrin-dependent major histocompatibility complex class I down-regulation. J Virol 2000; 74: 9256-9266.

77 Koppers-Lalic D, Reits EA, Ressing ME, Lipinska AD, Abele R, Koch J et al. Varicelloviruses avoid T cell recognition by UL49.5mediated inactivation of the transporter associated with antigen processing. Proc Natl Acad Sci USA 2005; 102: 5144-5149.

78 Tomazin R, Hill AB, Jugovic P, York I, van Endert P, Ploegh HL et al. Stable binding of the herpes simplex virus ICP47 protein to the peptide binding site of TAP. EMBO J 1996; 15: 3256-3266.

79 Lehner PJ, Karttunen JT, Wilkinson GW, Cresswell P. The human cytomegalovirus US6 glycoprotein inhibits transporter associated with antigen processing-dependent peptide translocation. Proc Natl Acad Sci USA 1997; 94: 6904-6909.

80 Berger C, Xuereb S, Johnson DC, Watanabe KS, Kiem HP, Greenberg PD et al. Expression of herpes simplex virus ICP47 and human cytomegalovirus US11 prevents recognition of transgene products by CD8(+) cytotoxic T lymphocytes. J Virol 2000; 74: 4465-4473.

81 Furukawa L, Brevetti LS, Brady SE, Johnson D, Ma M, Welling $\mathrm{TH}$ et al. Adenoviral-mediated gene transfer of ICP47 inhibits major histocompatibility complex class I expression on vascular cells in vitro. J Vasc Surg 2000; 31: 558-566.

82 Ayalon O, Hughes EA, Cresswell P, Lee J, O'Donnell L, Pardi R et al. Induction of transporter associated with antigen processing by interferon gamma confers endothelial cell cytoprotection against natural killer-mediated lysis. Proc Natl Acad Sci USA 1998; 95: 2435-2440.

83 Huard B, Fruh K. A role for MHC class I down-regulation in NK cell lysis of herpes virus-infected cells. Eur J Immunol 2000; 30: 509-515.

84 Scaria A, Sullivan JA, St George JA, Kaplan JM, Lukason MJ, Morris JE et al. Adenoviral vector expressing ICP47 inhibits adenovirus-specific cytotoxic $\mathrm{T}$ lymphocytes in nonhuman primates. Mol Ther 2000; 2: 505-514.

85 von Herrath MG, Efrat S, Oldstone MB, Horwitz MS. Expression of adenoviral E3 transgenes in beta cells prevents autoimmune diabetes. Proc Natl Acad Sci USA 1997; 94: 9808-9813.

86 Levitskaya J, Coram M, Levitsky V, Imreh S, SteigerwaldMullen PM, Klein G et al. Inhibition of antigen processing by the internal repeat region of the Epstein-Barr virus nuclear antigen-1. Nature 1995; 375: 685-688. 
87 Levitskaya J, Sharipo A, Leonchiks A, Ciechanover A, Masucci MG. Inhibition of ubiquitin/proteasome-dependent protein degradation by the Gly-Ala repeat domain of the Epstein-Barr virus nuclear antigen 1. Proc Natl Acad Sci USA 1997; 94: 12616-12621.

88 Ossevoort M, Zaldumbide A, Cramer SJ, van der Voort EI, Toes RE, Hoeben RC. Characterization of an immuno 'stealth' derivative of the herpes simplex virus thymidine-kinase gene. Cancer Gene Ther 2006; 13: 584-591.

89 Ossevoort M, Visser BM, van den Wollenberg DJ, van der Voort EI, Offringa R, Melief CJ et al. Creation of immune 'stealth' genes for gene therapy through fusion with the Gly-Ala repeat of EBNA-1. Gene Therapy 2003; 10: 2020-2028.

90 Tellam J, Sherritt M, Thomson S, Tellam R, Moss DJ, Burrows SR et al. Targeting of EBNA1 for rapid intracellular degradation overrides the inhibitory effects of the Gly-Ala repeat domain and restores CD8+ T cell recognition. J Biol Chem 2001; 276: 33353-33360.

91 Yewdell JW, Schubert U, Bennink JR. At the crossroads of cell biology and immunology: DRiPs and other sources of peptide ligands for MHC class I molecules. J Cell Sci 2001; 114: 845-851.

92 Yewdell JW, Nicchitta CV. The DRiP hypothesis decennial: support, controversy, refinement and extension. Trends Immunol 2006; 27: 368-373.

93 Ossevoort M, Zaldumbide A, Te Velthuis AJ, Melchers M, Ressing ME, Wiertz EJ et al. The nested open reading frame in the Epstein-Barr virus nuclear antigen-1 mRNA encodes a protein capable of inhibiting antigen presentation in cis. Mol Immunol 2007; 44: 3588-3596.

94 Manno CS, Pierce GF, Arruda VR, Glader B, Ragni M, Rasko JJ et al. Successful transduction of liver in hemophilia by
AAV-Factor IX and limitations imposed by the host immune response. Nat Med 2006; 12: 342-347.

95 Mount JD, Herzog RW, Tillson DM, Goodman SA, Robinson N, McCleland ML et al. Sustained phenotypic correction of hemophilia B dogs with a factor IX null mutation by liverdirected gene therapy. Blood 2002; 99: 2670-2676.

96 Wang L, Nichols TC, Read MS, Bellinger DA, Verma IM. Sustained expression of therapeutic level of factor IX in hemophilia B dogs by AAV-mediated gene therapy in liver. Mol Ther 2000; 1: 154-158.

97 Mingozzi F, Maus MV, Hui DJ, Sabatino DE, Murphy SL, Rasko JE et al. CD8(+) T-cell responses to adeno-associated virus capsid in humans. Nat Med 2007; 13: 419-422.

98 Mingozzi F, Hasbrouck NC, Basner-Tschkarajan E, Edmonson SA, Hui DJ, Sabatino DE et al. Modulation of tolerance to the transgene product in a non-human primate model of AAVmediated gene transfer to liver. Blood 2007: 2334-2341.

99 Zaldumbide A, Ossevoort M, Wiertz EJ, Hoeben RC. In cis inhibition of antigen processing by the latency-associated nuclear antigen I of Kaposi sarcoma herpes virus. Mol Immunol 2007; 44: 1352-1360.

100 Kwun HJ, da Silva SR, Shah IM, Blake N, Moore PS, Chang Y. Kaposi's sarcoma-associated herpesvirus latency-associated nuclear antigen 1 mimics Epstein-Barr virus EBNA1 immune evasion through central repeat domain effects on protein processing. J Virol 2007; 81: 8225-8235.

101 Bennett NJ, May JS, Stevenson PG. Gamma-herpesvirus latency requires $\mathrm{T}$ cell evasion during episome maintenance. PLoS Biol 2005; 3: e120.

102 Sharipo A, Imreh M, Leonchiks A, Branden C, Masucci MG. cisInhibition of proteasomal degradation by viral repeats: impact of length and amino acid composition. FEBS Lett 2001; 499: 137-142. 